\title{
Teorias Sobre o Amor no Campo da Psicologia Social
}

Theories About Love In The Field

Of Social Psychology

Teorías Sobre El Amor En El Campo

De La Psicología Social

Priscilla de Oliveira

Martins-Silva, Zeidi

Araujo Trindade \&

Annor da Silva Junior

Universidade Federal do Espírito Santo
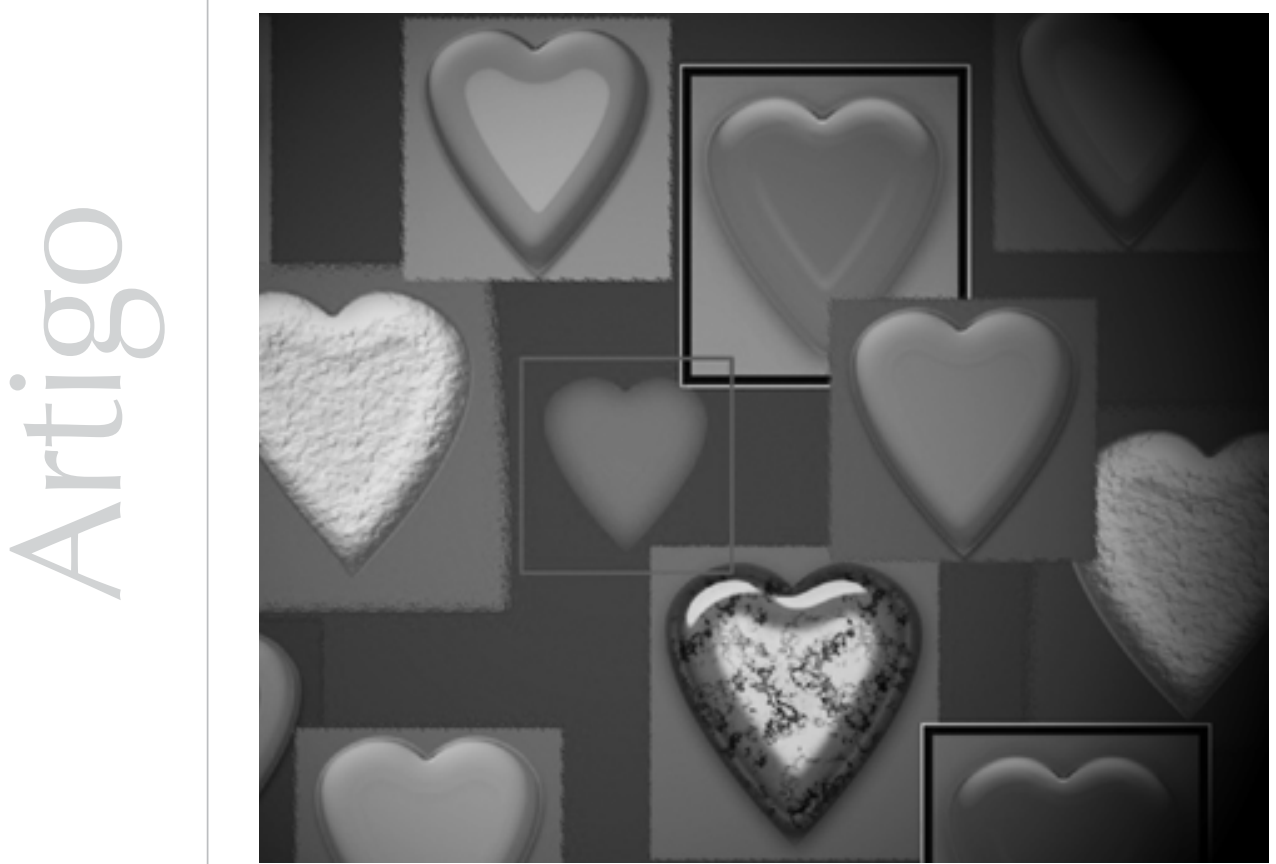
Resumo: Este é um ensaio teórico sobre o fenômeno amor em relacionamentos românticos no campo da Psicologia e no da Psicologia social. São apresentadas as primeiras teorias sobre o amor na Psicologia, e, posteriormente, são abordadas em maior profundidade três teorias da Psicologia social: os estilos de amor de John Alan Lee, a teoria de apego, de Phillip Shaver, Cindy Hazan e Donna Bradshaw, e a teoria triangular do amor, de Robert J. Sternberg. São apresentados os aspectos teóricos, empíricos e metodológicos de cada teoria, e sua análise permitiu observar que o amor é um fenômeno complexo e detectar a presença de divergências teóricas e metodológicas. A complexidade é observada na diversidade teórica e nos resultados de pesquisas encontrados. Teoricamente, foi registrada divergência na forma como o amor é concebido; metodologicamente, houve o predomínio de abordagens quantitativas, com a presença de diferentes escalas. Identifica-se que algumas questões precisam ser mais bem investigadas, assim como os instrumentos de medidas adotados. Nota-se, assim, que essa área de estudo ainda está em processo de evolução e que a realização de mais pesquisas pode contribuir para o desenvolvimento do campo. Ao final, sugere-se o estudo da interação da cultura via crenças e valores na vivência do amor e maior utilização de abordagens qualitativas.

Palavras-chave: Amor. Relações interpessoais. Psicologia social. Estados emocionais.

Abstract: The present study is a theoretical essay about the phenomenon of love in romantic relationships in the field of psychology and social psychology. The first theories on love in psychology are presented. After, three theories of social psychology are discussed in greater depth: love styles, by John Alan Lee, the adult attachment theory, by Phillip Shaver, Cindy Hazan and Donna Bradshaw, and the triangular theory of love, by Robert J. Sternberg. The contributions of each theory on theoretical, empirical and methodological issues are presented. Two aspects were observed: that love is a complex phenomenon and the presence of theoretical and methodological differences among the three theories. The complexity is observed in theoretical approach diversity and in research results. Theoretically, there is disagreement on how love is conceived. Methodologically, there is a predominance of quantitative research with different scales. It is observed that further investigation on the theme is needed, as well as on the scales adopted. Therefore, the love field of study is still in process of evolution, so further research may contribute to this field. It is suggested that it is important to study the interaction of culture, values and beliefs in the experience of love and to use more qualitative approaches in the research about love.

Keywords: Love. Interpersonal relationships. Social psychology. Emotional States.

Resumen: Este es un ensayo teórico sobre el fenómeno amor en relaciones románticas en el campo de la Psicología y en el de la Psicología social. Son presentadas las primeras teorías sobre el amor en la Psicología, y, posteriormente, son abordadas en mayor profundidad tres teorías de la Psicología social: los estilos de amor de John Alan Lee, la teoría de apego, de Phillip Shaver, Cindy Hazan y Donna Bradshaw, y la teoría triangular del amor, de Robert J. Sternberg. Son presentados los aspectos teóricos, empíricos y metodológicos de cada teoría, y su análisis permitió observar que el amor es un fenómeno complejo y detectar la presencia de divergencias teóricas y metodológicas. La complejidad es observada en la diversidad teórica y en los resultados encontrados de investigaciones. Teóricamente, se registraron divergencias en la forma de como el amor es concebido; metodológicamente, hubo el predominio de abordajes cuantitativos, con la presencia de diferentes escalas. Se identificó que algunas cuestiones necesitan ser mejor investigadas, así como los instrumentos de medidas adoptados. Se nota, así, que esa área de estudio aún está en proceso de evolución y que la realización de más investigaciones puede contribuir para el desarrollo del campo. Al final, se sugiere el estudio de la interacción de la cultura vía creencias y valores en la vivencia del amor y una mayor utilización de abordajes cualitativos.

Palabras claves: Amor. Relaciones interpersonales. Psicología social. Estados emocionales.

Pretende-se, neste ensaio teórico, realizar uma revisão da literatura científica sobre o amor em relacionamentos românticos no campo da Psicologia e no da Psicologia social. Para isso, serão destacadas e analisadas as principais teorias observadas na literatura. Os primeiros estudos sobre o amor na Psicologia datam da primeira década do século XX
(Rubin, 1988; Sternberg, 1997; Hendrick \& Hendrick, 1986). De acordo com Rubin (1988) e De Andrade (2011), desde esse período até os dias de hoje, muitas pesquisas foram realizadas com o objetivo de discutir o fenômeno. Para isso, foram propostas teorias sobre o amor (Freud, 1996/1922; Reik, 1944; Maslow, 1962; Rubin, 1970; Clark \& Mills, 
1979; Walster \& Walster, 1978; Lee, 1988; Shaver, Hazan, \& Bradshaw, 1988; Sternberg, 1988), levantados os benefícios e os prejuízos que uma relação amorosa pode trazer para os indivíduos (Dessen \& Braz, 2005) e avaliados os fatores que interferem e comprometem os relacionamentos amorosos (Sprecher \& Metts, 1999; Dessen \& Braz, 2005). Mais recentemente, o foco de atenção tem permanecido no entendimento dos fatores de satisfação e insatisfação do relacionamento conjugal e dos fatores de ajustamento e desajustamento das relações (Wachelke, De Andrade, Cruz, Faggiani, \& Natividade, 2004; De Andrade, 2011; Andrade, Garcia, \& Cano, 2009), especialmente aqueles que se referem à manutenção e à dissolução conjugal (Dessen \& Braz, 2005).

As pesquisas sobre o amor já consolidadas nos Estados Unidos (Graham \& Christiansen, 2009) ainda são consideradas incipientes no Brasil, porém, encontram-se em processo de evolução a partir da primeira década do século XXI (Andrade \& Walcheke, 2011). Nessa evolução, destaca-se que o amor tem sido objeto de estudo articulado com outros temas, como, por exemplo, a satisfação conjugal (Wachelke et al., 2004; Andrade, Garcia, \& Cano, 2009), os relacionamentos amorosos via internet (Dela Coleta, Dela Coleta, \& Guimarães, 2008), as habilidades sociais em relacionamentos românticos (Villa, Del Prette, \& Del Prette, 2007) e a compreensão do amor como uma representação social (Martins-Silva, 2009; Andrade \& Wachelke, 2011), entre outros. Além disso, o amor também tem sido estudado por meio de teorias específicas existentes, como o desenvolvimento da versão brasileira da Escala de Componentes do Amor (Hernadez, 1999; Cassepp-Borges, \& Teodoro, 2007; Gouveia, Fonseca, Cavalcanti, Diniz, \& Dória, 2009).

Mesmo diante do maior interesse de pesquisadores sobre o tema, constata-se que o amor como campo teórico de conhecimento na Psicologia e na Psicologia social ainda apresenta lacunas e inconsistências teóricas e metodológicas (Berscheid, 2006) que justificam a realização deste ensaio teórico. Proposta semelhante foi realizada por Reis (1992) ao apresentar as principais teorias, contudo, o presente artigo se distingue daquele por extrapolar a discussão ao apresentar os avanços teóricos e metodológicos realizados nestes mais de vinte anos.

Para a revisão de literatura, estruturou-se o texto em três partes além da introdução: (a) na segunda, apresentam-se, de forma sucinta, as teorias que deram origem à discussão sobre o amor em Psicologia, mais especificamente, no campo clínico da Psicologia (Sternberg, 1997), (b) na terceira parte, apresentam-se mais detalhadamente as teorias de maior repercussão (Graham, \& Christiansen, 2009) no campo da Psicologia social, e, (c) na quarta, são apresentadas as considerações finais.

\section{As primeiras teorias sobre o amor no campo clínico da Psicologia}

Com base em Sternberg (1997), pode-se afirmar que três são as primeiras teorias sobre o amor no campo da Psicologia. Todas nasceram do campo clínico da área, sendo duas da corrente psicanalista e uma da corrente humanista. Trata-se, respectivamente, das teorias de Sigmund Freud, de Theodor Reik e de Abraham H. Maslow.

Para Freud (1996/1922), o amor em relação a um objeto externo ocorre apenas após a construção do ideal de ego do indivíduo. Sendo assim, Freud, ao elaborar a teoria sobre o desenvolvimento psicossexual, propõe que a escolha de um objeto de amor externo só é possível quando o indivíduo teve primeiro 
toda a sua energia libidinal direcionada para si mesmo. Diante dessa proposição, Freud (1996/1914) elabora que o narcisismo é um aspecto importante para a construção de relações amorosas. O objeto de amor externo é, então, escolhido a partir daquilo que é observado como algo que falta ao indivíduo.

Outra teoria que procurou explicar o amor foi proposta por Reik (1944). Esse autor, também psicanalista, propõe uma teoria diferente da teoria psicanalista tradicional. Enquanto para Freud o amor está baseado na energia libidinal, ou seja, o amor e o desejo são um função do outro, para Reik, o amor e o desejo possuem diferentes forças motivadoras. Mais especificamente, o autor argumenta que o amor, diferentemente do desejo, que é um interesse apaixonado por um outro corpo, é um interesse apaixonado por outra personalidade.

A terceira teoria, pertencente à corrente humanista, foi proposta por Maslow (1962), e também contribuiu nessa fase inicial com proposições teóricas sobre o amor. O autor argumenta que existem dois tipos de amor; são eles: D-love (deficiency love/ amor deficiente) e B-love (being love/ amor) ${ }^{1}$. O primeiro tipo ( $D$-love) teria as propriedades do amor proposto por Freud, ou seja, o sentimento de amor em relação à outra pessoa surge com o objetivo de sanar as próprias deficiências; já o outro tipo ( $B$-love) ocorre entre pessoas auto-realizadoras, que podem amar outras pessoas pelo que elas de fato são.

Essas três proposições foram contribuições importantes para o estudo do amor e serviram, pelo menos em parte, de fundamento para

\section{Os estudos sobre o amor no campo da Psicologia social}

Este tópico do artigo está estruturado em quatro subtópicos: no primeiro, apresentamse as considerações iniciais acerca do desenvolvimento das teorias do amor na Psicologia social; no segundo, terceiro e quarto tópicos, abordam-se, respectivamente, a teoria dos estilos de amor, a teoria de apego (adulto), a teoria triangular do amor, bem como as considerações analíticas e as aplicações empíricas de cada uma dessas teorias.

\section{Considerações iniciais}

A primeira proposta teórica que abordou o amor romântico dentro da Psicologia social procurou fazer a distinção entre amar e gostar (Rubin, 1970). Nessa perspectiva, Rubin sustenta que o amor é uma atitude em relação a uma pessoa em particular que envolve uma predisposição para pensar, sentir e se comportar de certa forma em relação a essa pessoa. A partir da proposta de Rubin, outras propostas teóricas surgiram com o objetivo de definir o amor.

Walster e Walster (1978) definiram o amor em dois tipos: amor-companheiro e amorapaixonado. Essa teoria propõe que o amor possui dois estágios: o primeiro seria uma atração apaixonada que depois se transformaria em amor companheiro, caso o relacionamento sobrevivesse ao estágio inicial da paixão. Outra teoria surgida no mesmo período foi a proposta de Clark e Mills (1979). Esses autores estudaram a atração interpessoal em relacionamentos de troca e em relacionamentos românticos, e, de acordo com os resultados encontrados, propuseram que os relacionamentos de troca estão baseados em questões econômicas; já os relacionamentos em que existe amor estão baseados em motivos altruístas. 
Essas primeiras propostas teóricas, com exceção da proposta de Rubin, contribuíram no sentido de abordar o amor como um fenômeno complexo e multidimensional (Neto, 2007). Contudo, de acordo com Hendrick e Hendrick (1986), esses esforços eram muito mais teóricos do que empíricos. Uma proposta teórica que rompeu esse padrão foi a de John Alan Lee, a qual foi denominada estilos de amor.

\section{Os estilos de amor}

A teoria dos estilos de amor foi proposta inicialmente em 1970, e está baseada na concepção de que o amor é aprendido e que os estilos de amor refletem a diversidade humana nas maneiras de amar (Neto, 2007). Para definir os estilos de amor existentes nos relacionamentos humanos, Lee utilizou vários métodos. Primeiro, foi feito um levantamento do que seria amor em livros de romance, em filmes e em livros do campo de conhecimento da Filosofia e da Psicologia. Depois, foi feita uma categorização dos dados levantados, chegando-se aos estilos propostos. Para verificação da aplicabilidade desses estilos, foram realizadas entrevistas com pessoas heterossexuais e homossexuais, as quais confirmaram os tipos propostos (Lee, 1988).

Devido à complexidade do tema e à impossibilidade de afirmar quantos estilos de relacionamento existem, Lee parte da possibilidade de avaliar os tipos de relacionamento a partir de seus componentes primários, e usou a metáfora da roda de cores para explicar a sua teoria. Assim como as cores possuem cores primárias que, misturadas a outras cores primárias, formam cores diferentes, existem estilos de amor denominados primários que, ao serem misturados a outros estilos de amor, também primários, podem originar estilos de amor secundários. Os três estilos primários de amor que caracterizam as pessoas são:

Eros. Neste estilo, as pessoas sabem descrever de forma clara que tipo físico é o mais atrativo em sua concepção, e sentem grande excitação ao observar pessoas que se parecem com o tipo físico de seu gosto. Demonstram querer conhecer o amado de forma rápida e intensa e procuram expressar seu prazer em estar com o outro de forma verbal e tátil.

Ludus. Caracteriza-se pela diversão e pela falta de compromisso com um único parceiro. Está associado a pessoas que não querem comprometimento com o amor. Pessoas de estilo ludus acham que vários tipos físicos são atraentes e não veem contradição em amar vários parceiros igualmente ao mesmo tempo.

Storge. Neste estilo, o amor, para as pessoas, é uma amizade especial. Para elas, é importante conhecer o parceiro como um amigo, antes de qualquer interação sexual. Não se verifica uma preferência por um tipo físico, uma vez que a questão emocional está em primeiro plano.

Lee indica que, a partir dos três estilos de amor descritos, várias outras formas de amor com características diferentes podem ser derivadas. Contudo, o autor apresenta apenas seis tipos, chamados de estilos secundários. A seguir, estão caracterizados sucintamente os seis estilos.

Eros + ludus = mania. É caracterizado por ser irracional, obsessivo e dependente. As pessoas têm a necessidade de estar amando, mas têm medo de que o amor seja difícil e doloroso. Apresentam comportamentos exagerados para demonstrar o seu amor ou para demonstrar ciúmes. 
Os achados das pesquisas indicam que os estilos de amor são decorrência da socialização, e não de fator genético (Waller \& Shaver, 1994).
Ludus + storge $=$ pragma. As pessoas que possuem este estilo de amor são realistas e práticas, por isso estão em busca de um parceiro compatível, ou seja, que se adapte as suas expectativas. É mais provável que escolha um parceiro que tenha os mesmos interesses, a mesma classe social e a mesma religião, entre outros aspectos.

Eros + storge $=$ ágape. Caracterizado pelo amor fraternal, pela gentileza e pelo altruísmo. É o amor baseado na concepção do dever com o outro. Nesse sentido, é um amor baseado na disposição para se dedicar ao próximo e na ausência de cobranças em termos de reciprocidade.

\section{Storge + eros $=$ predomínio storge.} As pessoas que se enquadram neste tipo enfatizam mais os sentimentos de carinho e cuidado do que a intimidade sexual. Além disso, acreditam que o amor é um dever para aqueles que precisam, e que é essencial para uma vida completa.

Ludus + eros $=$ predomínio ludus. Este estilo é concebido como uma experiência interessante e divertida. Essas pessoas são caracterizadas pela facilidade em conhecer outras pessoas e pelo interesse em experimentar os diferentes tipos de relacionamentos, sem apresentar, contudo, grandes emoções em seus relacionamentos.

Storge + ludus $=$ predomínio storge $\mathrm{O}$ foco do relacionamento está em um convívio prazeroso, no qual as emoções são expressas de forma discreta. Para essas pessoas, o convívio ocorre quando é conveniente para ambas as partes, não havendo grandes alterações da rotina cotidiana em função do parceiro.

De acordo com Lee, as pessoas podem variar de um estilo para o outro segundo suas experiências da vida. O autor afirma, entretanto, que é importante avaliar qual o estilo preferencial do indivíduo em determinado momento, seja para autoconhecimento, seja para reconhecer o estilo de amor do parceiro, seja para procurar um parceiro com um estilo de amor mais adequado ao seu. Lee, em seu trabalho, procurou conhecer as diferentes maneiras de amar, mas deixou brechas para que a sua teoria fosse aprimorada, expandida e testada empiricamente.

\section{Considerações analíticas e aplicações empíricas}

A partir da teoria sobre os estilos de amor (Lee, 1988), diferentes autores procuraram testá-la por meio de escalas de atitude que conseguissem mensurar os seis estilos propostos (Lasswell \& Lasswell, 1976; Hendrick \& Hendrick, 1986). Dessa forma, com a proposta de testar a teoria, psicólogos sociais utilizaram o conceito de atitude para a identificação dos estilos propostos por Lee. A escala que obteve maior confiabilidade, consistência interna adequada e uma distribuição fatorial consistente com os seis estilos de amor foi a produzida por Hendrick e Hendrick, denominada LAS (Love Attitudes Scale). A medida no conjunto possuiu um total de 42 itens distribuídos igualmente entre os seis estilos de amor. A LAS foi utilizada de diversas formas com o objetivo de fornecer maior compreensão sobre a teoria dos estilos de amor e sobre o comportamento humano e o amor. Os achados das pesquisas indicam que os estilos de amor são decorrência da socialização, e não de fator genético (Waller \& Shaver, 1994), por isso, as questões de gênero (Hendrick \& Hendrick, 1986; Davies, 2001) e as diferenças culturais entre as diferentes sociedades (Neto, 2007), assim como as experiências amorosas anteriores e a situação em que se encontra o relacionamento amoroso (Hendrick \& Hendrick, 1986), interferem na atitude relativa ao amor. 
De acordo com esses achados, para os homens, os estilos mais desejáveis socialmente são eros e ludus, enquanto, para as mulheres, é o estilo ágape. É interessante notar que, para ambos (homens e mulheres), observou-se correlação negativa para o estilo mania (Davies, 2001). Em outra pesquisa que avaliou os tipos mais observados entre homens e mulheres, verificou-se que os homens assumem mais significativamente $o$ estilo ludus, e as mulheres, os estilos storge, pragma e mania (Hendrick \& Hendrick, 1986). As diferenças de gênero podem ser explicadas pelo tipo de socialização feminina e masculina (Davies, 2001; Hendrick \& Hendrick, 1986).

Sobre as diferenças culturais, as explicações são baseadas nas diferenças culturais em termos de individualismo e coletivismo (Neto, 2007). Neto, ao estudar alunos universitários portugueses, britânicos e indianos, identificou que os indianos revelaram escores mais elevados para pragma, mania e ágape do que os britânicos e os portugueses. Contudo, alguns achados não são consistentes nas diferentes pesquisas. Hendrick e Hendrick (1986), por exemplo, demonstraram que alunos universitários orientais (que possuem culturas coletivistas) possuem baixos escores para eros, enquanto Neto não observa essa diferença entre alunos universitários de cultura coletivista e individualista; a conclusão que Neto apresenta é que, em todo o mundo moderno, as pessoas experimentam o amor apaixonado de forma semelhante.

Diferenças nos estilos de amor também foram identificadas em relação à experiência amorosa anterior. Os indivíduos que relataram nunca ter amado tiveram escores baixos para eros e ágape, enquanto indivíduos que se apaixonaram mais de duas vezes tiveram escores elevados nesses dois estilos. Também foi observada diferença significativa para o estilo ludus. Os indivíduos que se apaixonaram mais de três vezes tiveram escore alto para ludus, e os indivíduos que se apaixonaram apenas uma vez tiveram escore baixo para ludus (Hendrick \& Hendrick, 1986).

Em um estudo brasileiro (Andrade \& Garcia, 2009) em que foi aplicada a escala proposta por Hendrick e Hendrick a 509 homens e mulheres recrutados em um site de relacionamentos, foi identificado que as pessoas que se declararam apaixonadas possuíam escores significativamente mais altos nas dimensões eros, ágape, ludus e mania, confirmando os achados de Hendrick e Hendrick, que indicam que a situação em que as pessoas se encontram no relacionamento amoroso interfere na maneira como o amor é avaliado. O coeficiente de confiabilidade alfa de Cronbach da versão brasileira das subescalas (por tipo de amor) variou de 0,55 a 0,81 . Os resultados da análise fatorial exploratória demonstraram consistência na estrutura com seis dimensões da escala, contudo, dos 42 itens iniciais, cinco foram excluídos após o procedimento fatorial, por não atingirem carga fatorial maior que 0,3 no respectivo fator.

Embora diferentes autores tenham contribuído para o teste empírico da teoria, observa-se que, em um estudo com o objetivo de realizar uma meta-análise (Graham \& Christiansen, 2009) sobre a confiança das medidas da escala proposta por Hendrick \& Hendrick, a consistência interna do instrumento nos itens eros, storge e mania era inferior a 0,7 se considerado o intervalo de confiança de 0,95. Além disso, os resultados demonstraram que nenhum modelo de regressão surgiu como estatisticamente significativo. Também foi observado que diferentes subescalas eram mais significativas de acordo com determinadas características dos participantes. A subescala eros, por exemplo, parece produzir resultados mais significativos com participantes casados do que com solteiros (Graham \& Christiansen, 2009). 
Esses achados revelam que o amor é um fenômeno complexo e que mais estudos precisam ser feitos para a sua compreensão. É possível que os instrumentos de medida propostos precisem ser revistos e ampliados no sentido de conseguir mensurar o que de fato têm por objetivo mensurar.

\section{A teoria do apego adulto}

A teoria do apego foi construída na década de 70 e no início dos anos 80, por J. Bowlby, em uma série de três volumes intitulada Attachament and Loss. A teoria tem como objetivo descrever e explicar, dentro de uma visão funcionalista e etológica, como bebês se tornam emocionalmente apegados à figura cuidadora e como sentem grande desconforto quando separados dessa figura (Shaver, Hazan, \& Bradshaw, 1988).

Essa teoria se baseia na proposição de que a evolução da espécie humana equipou o ser humano com vários sistemas de comportamentos que aumentam a possibilidade de sobrevivência e o sucesso reprodutivo. De acordo com Bowlby (2002), o sistema de apego é fundamental para o funcionamento dos outros sistemas, como o sistema exploratório, o sistema de acasalamento e o sistema de cuidado. $\mathrm{O}$ sistema de apego tem a função de possibilitar a proximidade entre o cuidador e o bebê, para que o cuidador, então, proteja o bebê de predadores e de outras ameaças à sobrevivência, e é composto por vários comportamentos, dentre os quais se podem citar: chorar, rir, pegar, andar e olhar, entre outros.

Shaver, Hazan e Bradshaw, com interesse em pesquisar sobre o amor e verificando que as pesquisas nesse campo possuíam um arcabouço teórico próprio limitado e ainda incipiente, propuseram a utilização da teoria de apego, de J. Bowlby, em estudos que envolvessem adultos. De acordo com os autores, o próprio Bowlby acredita que seja profícua a extensão de sua teoria para a compreensão do amor adulto, afirmando que o comportamento de apego é característico do ser humano em toda a sua existência.

Os estudos que relacionam a teoria do apego ao amor adulto partem do pressuposto que os modelos internos de funcionamento aprendidos na infância tendem a manter-se e a ser reforçados na interação com os outros. Isso acontece porque os indivíduos são propensos a se colocar em situações que reforçam os seus modelos precoces de funcionamento. As propostas mais representativas para a teoria de apego no adulto utilizam os três padrões de apego delineado por Mary Ainswoth: apego seguro, apego ansioso/ambivalente e apego evitativo (Shaver, Hazan, \& Bradshaw, 1988).

\section{Considerações analíticas e aplicações empíricas}

Com o objetivo de demonstrar que os comportamentos relacionados ao amor têm correspondência com os padrões de apego, Shaver, Hazan e Bradshaw (1988) aplicaram questionário no qual as pessoas deviam marcar as frases que mais se adequavam ao mais importante relacionamento amoroso que tiveram. A pesquisa foi aplicada aos leitores de um importante jornal de Denver (EUA) e replicada em uma população de universitários. De acordo com os resultados, a proporção de padrões de apego permaneceu estável nos dois estudos: $50 \%$ classificaram-se como pertencentes ao padrão seguro, $25 \%$, ao padrão evitativo e $25 \%$, ao padrão ansioso. Os dados não demonstraram diferenças de acordo com o sexo. Esses resultados, conforme os autores, não são diferentes dos encontrados por Mary Ainsworth em seus estudos com crianças.

Essa pesquisa também verificou que a forma como a pessoa descreve seu relacionamento 
está de acordo com o padrão de apego em que esse relacionamento se enquadra. As pessoas com padrão de apego seguro descrevem seus relacionamentos como felizes, amigáveis e confiáveis e enfatizam a capacidade de aceitar e de apoiar o parceiro apesar das suas falhas. Esses relacionamentos tendem a ser mais duradouros; em média, duram 10,02 anos. As pessoas com padrão evitativo apresentaram medo de intimidade, altos e baixos emocionais e ciúmes. O tempo de duração do relacionamento desses indivíduos foi, em média, de 5,97 anos. Já as pessoas com o padrão de apego ansioso indicaram experiências que envolvem obsessão, desejo de reciprocidade e união, altos e baixos emocionais, grande atração sexual e ciúmes. O tempo de duração dos relacionamentos dessas pessoas foi de 4,86 anos, em média. É importante considerar que, entre os três grupos, a média de idade era a mesma (36 anos).

Outra pesquisa verificou a relação entre o padrão de apego do adulto e as reações ao término de uma relação afetiva (Davis, Shaver, \& Vernon, 2003). Para isso, foi elaborado um questionário que utilizou a escala Close Relationships Mesures, de Brennan et al. (1988), que foi diponibilizado na internet. Os resultados demonstraram que o padrão de apego seguro estava associado a estratégias de enfrentamento sociais, ou seja, busca de amigos e família para suporte. Já o padrão de apego ansioso estava relacionado a grande preocupação de perda do parceiro, grande sofrimento físico e psíquico, tentativas exageradas de restauração do relacionamento, motivação sexual relacionada ao parceiro, comportamento irritadiço e vingativo, estratégias de enfrentamento disfuncionais e resolução desordenada. O padrão de apego evitativo apareceu fortemente associado à evitação e à estratégia de enfrentamento focada em si mesmo. Esse padrão também apareceu associado negativamente a sofrimento e a reações de busca de proximidade após o término do relacionamento.

Verifica-se, então, que os autores que propõem a teoria do apego buscam caracterizar os padrões de apego e relacionálos ao comportamento na relação amorosa. Essa teoria inovou a forma de conceber o amor, uma vez que utilizou como suporte teórico a Psicologia evolutiva, que pode ser considerada um marco teórico importante tanto para a Psicologia do desenvolvimento quanto para a Psicologia social (Shaver \& Mikulincer, 2006). Essa nova possibilidade de compreender o amor proporcionou uma ampliação na compreensão dos fatores que podem interferir na construção de um relacionamento amoroso; contudo, pesquisas ainda precisam ser feitas para entender como e porquê os sistemas de apego se desenvolvem da forma como o fazem (Shaver \& Mikulincer, 2006).

Uma questão que merece análise sobre a teoria do apego (adulto) é a proposição que a forma como se dá a relação entre o cuidador e a criança direciona como essa criança vai estabelecer laços amorosos em seu futuro. Essa proposição retira a ênfase no fato de que o indivíduo também faz parte de vários contextos sociais, além da família, que também, de alguma forma, influenciam o indivíduo. Estudos sobre resiliência, realizados por Werner e Smith (1982) e descritos por Yunes (2003), revelaram que algumas crianças que viveram em ambientes considerados de risco (pobreza, estresse perinatal, cuidados parentais deficientes pais alcoólatras ou com distúrbios mentais) não desenvolveram problemas relacionados à aprendizagem, ao comportamento ou aos aspectos afetivo-emocionais, ou seja, tornaram-se "adultos competentes capazes de amar, trabalhar, brincar/divertir-se e ter expectativas" (Yunes, 2003, p. 79). Esses achados indicam que outros fatores, além da família, também contribuem para a maneira 
como o indivíduo vai lidar com as relações afetivas em sua vida.

Os estudos sobre resiliência indicam que o ser humano pode manifestar resultados desenvolvimentais esperados (afetivo, comportamental e cognitivo) apesar dos riscos presentes no ambiente, que podem comprometer esse processo. Além disso, esses estudos também demonstram que, mesmo com a presença de riscos no ambiente, o nível de certas competências é mantido e que o ser humano possui a capacidade de recuperar-se das adversidades que experiencia ao longo da sua trajetória de vida (Silva, Elsen, \& Lacharité, 2003). Os resultados encontrados permitem verificar que os modelos afetivos aprendidos na vivência familiar são de grande importância para o indivíduo, mas isso não significa que esses modelos sejam inteiramente reproduzidos.

Essa teoria, embora tenha buscado entender o comportamento humano de maneira abrangente, utilizando em seu corpo teórico conceitos de etologia e de aprendizagem como os de adaptação e flexibilidade, limita as possibilidades humanas de mudança. Vários autores questionam a generalização dos padrões de interação primários para as relações futuras, durante o ciclo vital (Dalbem \& Dell'Aglio, 2005).

Quanto à consistência da teoria do apego (Bowlby, 2002), outros questionamentos também podem ser feitos. Beslky (1999), de acordo com Dalbem e Dell'Aglio (2005), por exemplo, questiona sobre o que leva algumas crianças a desenvolverem um apego seguro com seus cuidadores, enquanto outras crianças estabelecem um padrão de apego inseguro, e questiona, ainda, por que algumas crianças desenvolvem apego seguro mesmo que os cuidadores não estejam tão próximos.
Esses são questionamentos que apontam as lacunas e as limitações da teoria do apego. Dessa forma, embora as pesquisas nessa perspectiva tenham mostrado relevância científica, mais pesquisas devem ser realizadas para que essas perguntas sejam respondidas.

\section{A teoria triangular do amor}

Para Sternberg (1988; 1997), elaborador da teoria triangular do amor, esse sentimento é composto por três elementos básicos: comprometimento/decisão, intimidade e paixão. De acordo com Beach e Tesser (1988), os três elementos propostos por Sternberg estão presentes em várias discussões sobre o tema.

O primeiro elemento é o comprometimento/ decisão, que é entendido sob dois aspectos: um de curto prazo e outro de longo prazo. O aspecto de curto prazo refere-se à decisão sobre a existência de amor na relação, ou seja, se um dos pares ama o outro, e o aspecto de longo prazo está relacionado ao comprometimento em manter o amor (Sternberg, 1988).

O segundo aspecto é a intimidade, que, para Sternberg ( 1988; 1997), se refere à proximidade e aos laços emocionais no relacionamento a dois. Em um estudo sobre a intimidade (Thelen, Wal, Thomas, \& Harmon, 2000), foi verificado que essa questão representa um fator importante da vida humana, por isso, a dificuldade em estabelecer intimidade com outros pode trazer consequências negativas para a vida do indivíduo. Inclusive, é interessante ressaltar que problemas relacionados à intimidade estão entre as razões mais comuns que levam os casais a procurarem a psicoterapia (Thelen et al., 2000).

O terceiro aspecto descrito por Sternberg (1988; 1997) é a paixão, que, para o autor, 
significa atração física e consumação sexual. Acrescenta ele, entretanto, que, apesar de a atração física e a consumação sexual serem os componentes principais, em alguns relacionamentos, outros aspectos podem contribuir para a paixão, como a autoestima, a afiliação, a dominância e a submissão, entre outros.

A partir da delimitação dos três elementos fundamentais para a existência do amor, Sternberg (1988) argumenta que é possível fazer a combinação desses elementos e obter diferentes tipos de amor. Para melhor compreensão, o autor correlaciona a sua teoria à figura geométrica do triângulo. Dessa forma, os três elementos formam os três vértices do triângulo, e, combinados, formam os sete tipos de amor propostos, apresentados por meio da Figura 1, a seguir. É a partir dessa referência que o autor denominou a teoria de teoria triangular do amor.

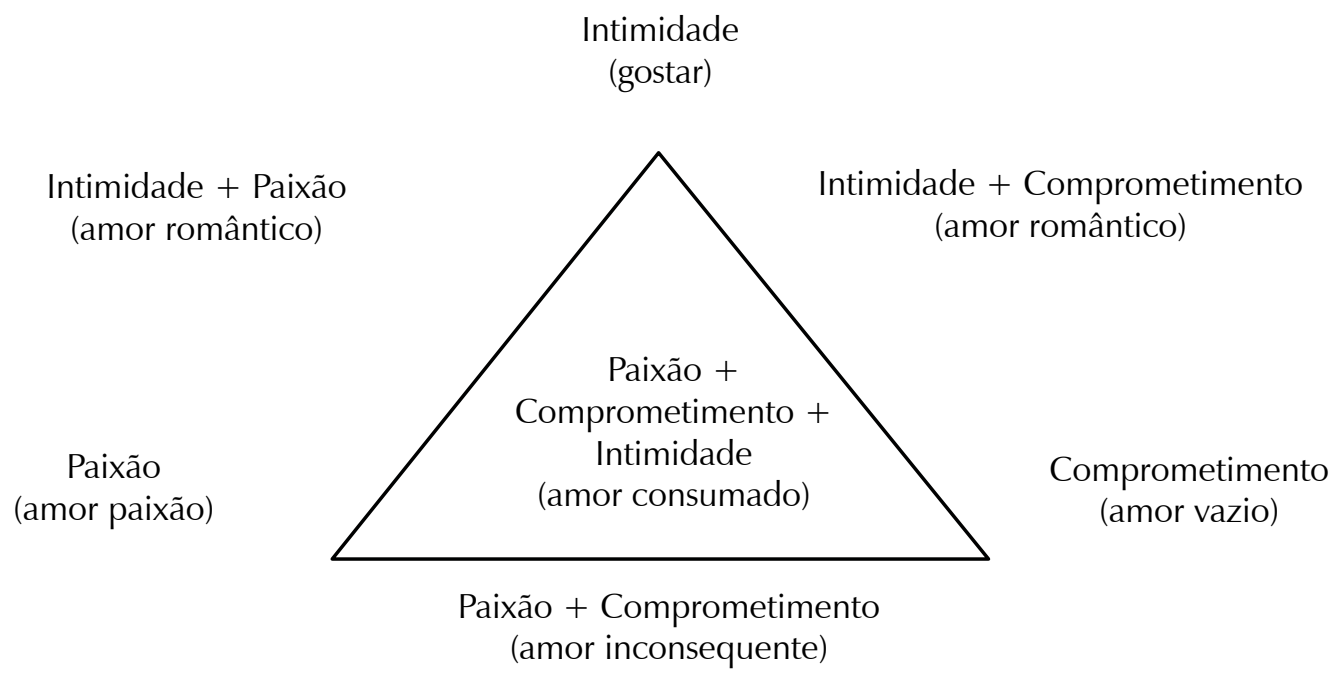

Figura 01. Os tipos de amor de acordo com a combinação dos três elementos do amor Fonte: Sternberg (1988, p. 122)

A seguir, far-se-á sucintamente a descrição de cada um dos tipos de amor propostos:

Gostar (elemento intimidade isolado). Tipo de amor presente nos relacionamentos de amizade. A pessoa pode se sentir próxima de outra e querer bem, mas sem a presença de intensa paixão ou de um comprometimento de longo tempo.

Paixão (elemento paixão isolado). Esse tipo de amor é caracterizado pela grande excitação mental e física. O indivíduo tende a idealizar o seu objeto de amor e a ter certa obsessão por ele.

Amor vazio (elemento comprometimento isolado). Tipo de amor geralmente presente em 
relacionamentos de longo tempo, em que já estiveram presentes a paixão e a intimidade, mas em que, por diversas razões, esses elementos se dissiparam.

Amor romântico (intimidade associada à paixão). As pessoas envolvidas com base no amor romântico sentem-se atraídas pelo outro emocional e fisicamente. Com o tempo, podem perceber que a permanência do relacionamento é improvável ou ainda achar que o comprometimento é algo com que devem lidar apenas em um momento futuro.

Amor companheiro (intimidade associada a comprometimento). Esse tipo de amor está presente em relacionamentos de amizade de longo prazo, e é mais característico de casamentos em que a atração física, maior fonte da paixão, já declinou.

Amor inconsequente (paixão associada a comprometimento). Tipo de amor característico de relacionamentos baseados em amor à primeira vista. O comprometimento no relacionamento desse tipo está embasado na paixão, por isso, quando a paixão se desvanece, qualquer problema pode fazer com que o relacionamento acabe.

Amor consumado (composto pelos três elementos básicos). Esse tipo de amor, na visão do autor, é aquele que a maioria das pessoas procura, pois ele consegue compor todos os elementos importantes para o relacionamento afetivo/amoroso.

Além dos tipos de amor descritos, Sternberg (1988) salienta que cada indivíduo possui o seu triângulo amoroso em um relacionamento conjugal. Para elucidar a sua proposta, ele utiliza os conceitos da geometria e revela que é possível a existência de triângulos equiláteros, nos quais todos os elementos estão em equilíbrio, e de triângulos não equiláteros, nos quais há predominância de um ângulo sobre os demais. É importante ressaltar que o triângulo de cada indivíduo se modifica com o tempo, pois, segundo o autor, cada um dos três elementos possui tempo de evolução diferente. Pressupondo que cada indivíduo possua o seu triângulo amoroso, o autor indica que, para que um relacionamento seja bem sucedido, os triângulos amorosos dos indivíduos na dupla amorosa devem ser similares e evoluir ou modificar-se ao longo do tempo também de forma similar.

O objetivo de Sternberg, ao propor a sua teoria, é poder diagnosticar os relacionamentos e tratá-los de forma terapêutica. De acordo com a teoria, as divergências conjugais podem ser resultado de formato de triângulos divergentes.

\section{Considerações analíticas e aplicações empíricas}

No sentido de contribuir para a validação de sua teoria, Sternberg (1997) formulou uma escala para mensurar os três fatores propostos. Os resultados encontrados, de acordo com o autor, são encorajadores, uma vez que a escala mostrou possuir validade interna (todos os coeficientes alfa de Cronbach para cada subescala foram superiores a 0,90) e externa (correlação de 0,76 para as três subescalas).

No Brasil, três estudos foram feitos com o objetivo de avaliar as propriedades psicométricas da Escala Triangular do Amor de Sternberg (ETAS) e de adaptá-la à língua portuguesa (Hernandez, 1999; CasseppBorges \& Teodoro, 2007; Golveia et al., 2009). Os três estudos indicam que a escala proposta por Sternberg tem problemas em relação à análise fatorial, pois há itens que não são saturados nos fatores esperados. Sendo assim, os três estudos propõem uma versão 
reduzida da escala, na qual as propriedades psicométricas sejam mais adequadas.

Uma discussão detalhada sobre os problemas encontrados na escala proposta por Sternberg é feita por Acker e Davis (1992). Segundo os autores, quando se observa uma elevada saturação de itens em fatores não esperados, é difícil defender a concepção de que existem fatores independentes, ou seja, que existem diferentes constructos que expliquem o amor. Nesse sentido, é bem mais provável que exista apenas um fator a ser explicado pela escala.

Os resultados encontrados até o momento indicam que a teoria ainda está em construção, e, por isso, mais estudos precisam ser feitos no sentido de entender melhor a relação desses três componentes com a experiência do amor. Um estudo interessante nesse sentido é realizado por Yela (1996), no qual se verifica que é possível dividir o fator paixão em dois outros fatores: paixão erótica e paixão romântica. Todavia, a escala com três fatores (Sternberg, 1997) demonstra ser mais plausível do ponto de vista psicométrico (Cassepp-Borges \& Teodoro, 2007).

Em um estudo de meta-análise (Graham \& Christiansen, 2009), é verificado que a escala utilizada para avaliar as atitudes em relação aos três componentes do amor possui consistência interna adequada, com coeficiente de confiabilidade alfa de Cronbach de 0,9; contudo, observa-se certa interferência das características dos participantes em duas subescalas. A escala paixão apresentou maior significância estatística para pessoas brancas do que para pessoas não brancas, e a escala compromisso foi negativamente associada ao tempo de relacionamento. Além disso, os dados da meta-análise são consistentes com os resultados das pesquisas anteriores que indicam que a ETAS é uma medida para avaliar o amor romântico como um único fator (Graham \& Christiansen, 2009).

Os dados encontrados até o momento sobre a teoria triangular do amor demonstram que, embora os três componentes do amor propostos estejam presentes em vários estudos, o instrumento proposto para analisar os três fatores da teoria triangular do amor não tem se mostrado consistente com a proposição dos três fatores. Diante dessa realidade, é de grande relevância que o instrumento e a teoria possam ser revistos e ampliados com o objetivo de conseguir explicar melhor o fenômeno do amor.

\section{Considerações finais}

Ao abordar a temática do amor neste ensaio teórico, alguns aspectos merecem destaque e considerações. Diante de distintas formas de conceber o amor, verificam-se divergências teóricas e metodológicas, o que indica pelo menos um ponto de consenso: a complexidade em abordar o fenômeno desses dois pontos de vista.

A complexidade é observada tanto na diversidade teórica quanto nos resultados encontrados. Teoricamente, verifica-se que duas teorias (teoria dos estilos de amor e teoria triangular do amor) entendem o amor como uma atitude, e que a terceira teoria concebe o amor como reflexo dos modelos internos de funcionamento aprendidos na infância. Sobre as duas primeiras teorias, verificam-se questões relacionadas aos instrumentos utilizados que merecem maiores estudos, questões essas referentes tanto a questões psicométricas (teoria dos estilos de amor e teoria triangular do amor) quanto à validade do constructo (teoria triangular do amor). Sobre a terceira teoria, verificam-se questionamentos relacionados à própria proposta teórica abordada que também precisam ser esclarecidos. 
Os resultados encontrados até o momento apresentam achados que contribuem para melhor compreensão do fenômeno amor, inclusive, é importante ressaltar que a tentativa de criar teorias que abarquem e sistematizem a complexidade do amor é válida e merece reverência; todavia, ainda existem muitas lacunas a serem preenchidas. Com o intuito de contribuir para a ampliação dos estudos sobre o amor, sugerem-se dois caminhos, além dos já mencionados anteriormente: compreender melhor a interação da cultura via crenças e valores na vivência do amor e maior utilização de abordagens qualitativas nas pesquisas.

Os dados demonstrados pela meta-análise realizada por Graham e Christiansen, com os dados da pesquisa de Neto (2007) e de Waller e Shaver (1994), indicam que as formas humanas de amar são influenciadas pelo processo de socialização, e revelam a importância de considerar a cultura e as crenças na proposta de compreensão do amor. Vários autores já têm demonstrado a importância da cultura no estudo do amor, já que este pode tomar diferentes formas de acordo com o contexto cultural e social (Beach \& Tesser, 1988; Sprecher \& Metts,
1999; Andrade \& Wachelke, 2011). Nesse sentido, acredita-se que o estudo das crenças e dos valores específicos de cada cultura e sociedade possam contribuir para ampliar a compreensão do fenômeno.

Outro aspecto que pode contribuir para o aprofundamento do tema é a integração de metodologias qualitativas nos estudos sobre o amor. Observa-se maior número de pesquisas quantitativas do que qualitativas relacionadas às propostas teóricas discutidas. As metodologias qualitativas têm como principais características positivas justamente o fato de serem utilizadas em objetos complexos (Flick, 2004) e de fundamentarem-se em uma estratégia baseada em dados coletados em interações sociais ou interpessoais, analisadas a partir dos significados dos sujeitos e/ou do pesquisador (Chizotti, 1998).

Espera-se que este ensaio teórico sirva de fundamento para a realização de novas pesquisas sobre o tema, principalmente na realização de estudos teóricos e empíricos que possam contribuir para melhor compreensão do fenômeno. Afinal, o tema é instigante, e mesmo os poetas, em suas abstrações, apresentam dificuldades em decifrá-lo. 


\section{Priscilla de Oliveira Martins-Silva}

Doutora em Psicologia pela Universidade Federal do Espírito Santo, Vitória - ES - Brasil.

E-mail: priscillamartinssilva@gmail.com

\section{Zeidi Araujo Trindade}

Doutora em Psicologia pela Universidade de São Paulo e professora titular da Universidade Federal do Espírito Santo, Vitória - ES - Brasil.

E-mail: zeid@aol.com.br

\section{Annor da Silva Junior}

Doutor em Administração pela Universidade Federal de Minas Gerais e professor adjunto da Universidade Federal do Espírito Santo, Vitória - ES - Brasil.

E-mail: annorsj@fucape.br

Endereço para envio de correspondência:

Avenida Fernando Ferrari, 514, Goiabeiras. CEP: 29075-910. Vitória, ES.

Recebido 20/07/2011, 1a Reformulação 15/03/2012, Aprovado 13/04/2012.

Acker, M., \& Davis, M. H. (1992). Intimacy, passion and commitment in adult romantic relationships: A test of the triangular theory of love. Journal of Social and Personal Relationships, 9, 21-50.

Andrade, A. L. D., Garcia, A., \& Cano, D. S. (2009). Preditores da satisfação global em relacionamentos românticos. Psicologia: Teoria e Prática, 11(3), 143-156.

Andrade, A. L. D., \& Wachelke, J. (2011). The association of structural configurations of romantic relationships with beliefs about couple relationships: A social representations study. Anales de Psicología, 27, 834-842.

Andrade, A. L. D., \& Garcia, A. (2009). Atitudes e crenças sobre o amor: versão brasileira da Escala de Estilos de Amor. Interpersona, 3(1), 89-102.

Beach, S. R. H., \& Tesser, A. (1988). Love in marriage: A cognitive account. In R. J. Sternberg \& M. L. Barnes (Eds.). The Psychology of Love (pp. 330-358). New York: Yale University.

Belsky, J. (1999). Interactional and contextual determinants of attachment security. In J. Cassidy \& P. Shaver (Eds.). Handbook of attachment: Theory, research and clinical applications (pp. 249-264). London: The Guildford Press.

Berscheid, E. (2006). Searching for the meaning of "love". In R. J. Sternberg \& K. Weis (Eds.). The new psychology of love (pp. 171-183). New Haven: Yale.

Brennan, K. A., Clark, C. L., \& Shaver, P. R. (1998). Self-report measurement of adult attachment: An integrative overview. In J. A. Simpson \& W. S. Rholes (Eds.), Attachment theory and close relationships (pp. 46-76). New York: Guilford.

Bowlby, J. (2002). Apego: a natureza do vínculo (3a. ed.). São Paulo: Martins Fontes
Cassepp-Borges, V., \& Teodoro, M. (2007). Propriedades psicométricas da versão brasileira da Escala Triangular do Amor de Sternberg. Psicologia: Reflexão e Crítica, 20(3), 513-522.

Clark, M. S., \& Mills, J. (1979). Interpersonal attraction in exchange and communal relationships. Journal of Personality and Social Psychology, 37, 12-24.

Chizzotti, A. (1998). Pesquisa em ciências humanas e sociais. São Paulo: Cortez.

Dalbem, J. X., \& Dell'Aglio, D. D. (2005). Teoria do apego: bases conceituais e desenvolvimento dos modelos internos de funcionamento. Arquivos Brasileiros de Psicologia, 57(12), 3-27.

Davies, M. F. (2001). Socially desirable responding and impression management in the endorsement of love styles. The Journal of Social Psychology, 135(5), 562-570.

Davis, D., Shaver, R., \& Vernon, M. L. (2003). Physical, emotional, and behavioral reactions to breaking up: The roles of gender, age, emotional involvement, and attachment style. Personality and Social Psychology Bulletin, 29(7), 871-884.

De Andrade, A. (2011). Relacionamentos românticos: modelos de qualidade e satisfação em relacionamentos de casal. Tese de doutorado. Programa de Pós-Graduação em Psicologia, Universidade Federal do Espírito Santo, Vitória, ES.

Dela Coleta, A. S. M., Dela Coleta, M. F., \& Guimaraes, J. L. (2008). O amor pode ser virtual? O relacionamento amoroso pela internet. Psicologia em Estudo, 13(2), 277-285.

Dessen, M. A., \& Braz, M. P. (2005). As relações maritais e sua influência nas relações parentais: implicações para o desenvolvimento da criança. In M. A. Dessen \& A. L. Costa Junior (Orgs.). A ciência do desenvolvimento humano: tendências atuais e perspectivas futuras (pp. 132-151). Porto Alegre: Artmed. 
Flick, U. (2004). Posturas teóricas. In U. Flick. Uma introdução à pesquisa qualitativa. Porto Alegre: Bookman.

Freud, S. (1996). Alguns mecanismos neuróticos no ciúme, na paranóia e no homossexualismo. In Edição standard brasileira das obras completas de Sigmund Freud (V. XVIII, pp. 271-281). Rio de Janeiro: Imago (Trabalho original publicado em 1922).

Freud, S. (1996). Sobre o narcisismo: uma introdução. In Edição standard brasileira das obras completas de Sigmund Freud (V. XIV, pp. 75-109). Rio de Janeiro: Imago (Trabalho original publicado em 1914).

Graham, J. M., \& Christiansen, K. (2009). The reliability of romantic love: A reliability generalization meta-analysis. Personal Relationships, 16, 49-66.

Gouveia, V. V., Fonseca, P. N., Cavalcanti, J. P. N., Diniz, P. K. C., \& Dória, L. C. (2009). Versão abreviada da Escala Triangular do Amor: evidências de validade fatorial e consistência interna. Estudos de Psicologia, 14(1), 31-39.

Hendrick, C., \& Hendrick, S. (1986). A theory and method of love. Journal of Personality and Social Psychology, 50(2), 392-402.

Hernandez, J. A. E. (1999). Validação da estrutura da Escala Triangular do Amor: análise fatorial confirmatória. Aletheia, 9, 15-26.

Lasswell, T. E., \& Lasswell, M. E. (1976). I love you but I am not in love with you. Journal of Marriage and the Family, 38, 211-224.

Lee, J. A. (1988). Love-styles. In R. J. Sternberg \& M. L. Barnes (Eds.). The psychology of love (pp. 38-67). New York: Yale University.

Martins-Silva, P. O. (2009). Vivendo casamentos, separações e recasamentos: um estudo sobre o campo representacional da conjugalidade. Tese de doutorado. Programa de PósGraduação em Psicologia, Universidade Federal do Espírito Santo, Vitória , ES.

Maslow, A. H. (1962). Toward a psychology of being. Princeton, NJ: Van Nostrand.

Neto, F. (2007). Love styles: A cross-cultural study of British, Indian, and Portuguese college students. Journal of Comparative Family Studies, 38(2), 239-254.

Reik, T. (1944). A psychologist looks at love. New York: Farrar \& Rinehart.

Reis, B. F. (1992). O amor à luz da psicologia científica. Psicologia: Reflexão \& Crítica, 5, 23-40.

Rubin, Z. (1970). Measurement of romantic love. Journal of Personality and Social Psychology, 16(2), 265-73.

Rubin, Z. (1988). Preface. In R. J. Sternberg \& M. L. Barnes (Eds.). The psychology of love (pp. VII - XII). New York: Yale University.

Shaver, P. R., \& Mikulincer, M. (2006). A behavioral system approach to romantic love relationships: Attachment, caregiving, and sex. In R. J. Sternberg \& K. Weis (Eds.). The new psychology of love (pp. 35-64). New Haven: Yale.

Shaver, P., Hazan, C., \& Bradshaw, D. (1988). Love as attachament: The integration of three behavioral systems. In R. J. Sternberg \& M. L. Barnes (Eds.). The psychology of love (pp. 264-292). New York: Yale University.

Silva, M. R. S., Elsen, I., \& Lacharité, C. (2003). Resiliência: concepções, fatores associados e problemas relativos à construção do conhecimento na área. Paidéia, 13(26), 147156.

Sprecher, S., \& Metts, S. (1999). Romantic beliefs: Their influence on relationships and patterns of change overtime. Journal of Social and Personal Relationships, 16(6), 834-851.

Sternberg, R. J. (1997). Construct validation of a triangular love scale. European Journal of Social Psychology, 27, 313-335.

Sternberg, R. J. (1988). Triangulating love. In R. J. Sternberg \& M. L. Barnes (Eds.). The psychology of love (pp.119-138). New York: Yale University.

Thelen, M. K., Wal, J. S. V., Thomas, A. M., \& Harmon, R. (2000). Fear of intimacy among dating couples. Behavior Modification, 24(2), 223-240

Villa, M. B., Del Prette, Z. A. P., \& Del Prette, A. (2007). Habilidades sociais conjugais e filiação religiosa: um estudo descritivo. Psicologia em Estudo, 12(1), 23-32.

Wachelke, J. F. R., De Andrade, A. L., Cruz, R. M., Faggiani, R. B., \& Natividade, J. C. (2004). Medida da satisfação em relacionamento de casal. Psico-USF, 9(1), 11-18.

Waller, N. G., \& Shaver, P. R. (1994). The importance of nongenetic influences on romantic love styles: A twin-family study. Psychological Science, 5(5), 268-274.

Walster, E., \& Walster, G. W. (1978). A new look at love. Reading, MA: Addison-Wesley.

Yela, C. (1996). Componentes básicos del amor: algunas matizaciones al modelo de Sternberg. Revista de Psicologia Social, 11(2), 185-201.

Yunes, M. A. M. (2003). Psicologia positiva e resiliência: o foco no indivíduo e na família. Psicologia em Estudo, 8(Esp.), 75-84. 